\title{
AS PLATAFORMAS INFORMÁTICAS NA ORGANIZAÇÃO ESCOLAR: modernização ou burocratização?
}

\author{
Maria João de Carvalho' \\ Armando Loureiro²
}

\section{RESUMO}

A crescente importância que as plataformas informáticas têm vindo a adquirir na organização escolar obriga à compreensão das suas potencialidades e centralidade enquanto instrumento ao serviço da eficiência e eficácia, conceitos caros à modernidade. O seu propósito confunde-se com a superação da burocracia e, assim sendo, terá como função contribuir para um quotidiano organizacional liberto das amarras do controlo, do centralismo, da padronização e uniformização e, em última instância, dos documentos escritos. Neste âmbito, e em particular no que concerne às plataformas informáticas, foi nosso propósito compreender se elas concorrem para reforçar ou para superar a burocracia na organização escolar. Para o efeito, realizamos uma investigação de natureza qualitativa, que configura um estudo de caso, um Agrupamento de Escolas no Norte de Portugal, que envolve o diretor e professores com cargo e sem cargo. Teve como instrumentos de recolha de dados a entrevista semiestruturada e a análise de conteúdo como técnica utilizada no tratamento dos dados. Foi possível concluir que as plataformas informáticas intensificam a burocracia pelo aumento da padronização, do controlo, da impessoalidade, pela omissão do interlocutor e pela valorização da tecnicidade tecnológica.

Palavras-chave: Plataformas informáticas. Burocracia. Organização escolar.

\section{THE COMPUTER PLATFORM IN THE SCHOOL ORGANIZATION:}

\section{modernization or bureaucratization?}

\begin{abstract}
The growing importance that computer platforms have been acquiring in the school organization requires an understanding of its potential and centrality as an instrument at the service of efficiency and effectiveness, concepts dear to modernity. Its purpose is confused with the overcoming of bureaucracy and,

\footnotetext{
1 Doutora em Educação-área de especialização em Organização e Administração Escolar. Universidade de Trás-os-Montes e Alto Douro (UTAD), Portugal. Centro de Investigação e Intervenção Educativas (CIIE) da Universidade do Porto, Portugal. ORCID https://orcid.org/0000-0002-6870-849X.E-mail:mjcc@utad.pt

2 Doutor em Educação-área de especialização em Sociologia da Educação. Universidade de Trás-os-Montes e Alto Douro (UTAD), Portugal. Centro de Investigação e Intervenção Educativas (CIIE) da Universidade do Porto, Portugal. ORCID https://orcid.org/0000-00033039-3872. E-mail: aloureiro@utad.pt
} 
therefore, it will have the function of contributing to an organizational daily life freed from the bonds of control, centralism, standardization and, ultimately, written documents. In this context, and regarding computer platforms, it was our purpose to understand whether they contribute to reinforce or to overcome bureaucracy in the school organization. For this purpose, we carried out a qualitative investigation, which sets up a case study, a Grouping of Schools in the North of Portugal, which involves the principal and teachers with and without charge. The data collection instruments were semi-structured interviews and content analysis was the technique used in data processing. It is possible to conclude that computer platforms intensify bureaucracy by increasing standardization, control, impersonality, by omitting the interlocutor and by valuing technological technicity.

Keywords: Computer platforms. Bureaucracy. School organization.

\section{LA PLATAFORMA DE COMPUTADORA EN LA ORGANIZACIÓN ESCOLAR: ¿modernización o burocratización?}

\section{RESUMEN}

La creciente importancia que han ido adquiriendo las plataformas informáticas en la organización escolar exige la comprensión de su potencialidad y centralidad como instrumento al servicio de la eficiencia y la eficacia, conceptos caros a la modernidad. Su finalidad se confunde con la superación de la burocracia y, por tanto, tendrá la función de contribuir a una vida diaria organizativa liberada de los lazos de control, centralismo, estandarización y estandarización y, en definitiva, documentos escritos. En este contexto, y particularmente en lo que respecta a las plataformas informáticas, fue nuestro propósito comprender si contribuyen a reforzar o superar la burocracia en la organización escolar. Para ello, llevamos a cabo una investigación cualitativa, que configura un caso de estudio, una Agrupación de Escuelas en el Norte de Portugal, que involucra al director y profesores con y sin cargo. Los instrumentos de recolección de datos fueron entrevistas semiestructuradas y el análisis de contenido ha sido la técnica utilizada en el procesamiento de datos. Se pudo concluir que las plataformas informáticas intensifican la burocracia al incrementar la estandarización, el control, la impersonalidad, al omitir al interlocutor y al valorar la tecnicidad tecnológica.

Palabras clave: Plataformas informáticas. Burocracia. Organización escolar.

\section{INTRODUÇÃO}

O elogio às tecnologias de informação e comunicação, transversal a várias áreas da sociedade, é a expressão de um discurso ideologicamente comprometido com as ideias de modernização, eficiência e eficácia. De resto, os discursos políticos de cariz gestionário reconhecem a informatização dos serviços como o corolário para se ultrapassar a burocracia. 
A educação não foi marginal a este ímpeto tecnológico que acabaria por extrapolar da sala de aula para as dinâmicas de administração e gestão escolar, ora definindo tempos de ação, ora potenciando a reconfiguração das estruturas organizacionais em consequência das tecnologias de informação de que dispõe.

O diverso software que permite a gestão de horários, de faltas, de vencimentos, de avaliação, de ação social escolar, de despesas são alguns dos exemplos que revelam a profusão de tecnologias ao serviço do planeamento, da organização e da coordenação.

\section{A BUROCRACIA NA ORGANIZAÇÃO ESCOLAR}

As consequências resultantes da multiplicidade e heterogeneidade de empresas que proliferaram no quadro da Revolução Industrial, com destaque para o baixo rendimento e perdas com origem em decisões mal formuladas, fizeram do século XIX, pelas condições profícuas que apresentou, o início sistemático dos estudos organizacionais que culminou no século XX (LIMA, 1998) com a proposta de uma administração científica (scientific management) em que o improviso e o empirismo cedem lugar ao império da lei, confirmando a forte e incontestável importância arrecadada pela racionalidade clássica que se vai fazendo sentir nos mais diversos domínios. Neste contexto, como referem Burrell e Morgan (1992, p. 128),

The world of organizations is treated as if were the world of natural phenomena, characterized by a hard concrete reality which can be systematically investigated in a way which reveals its underlying regularities. Above all else it is a word of cause and effect, the task of management theorist is seen as the identification of the fundamental laws which characterize its day-to-day operation.

Desta feita, a organização passa a ser governada de acordo com 'princípios científicos' que evitarão procedimentos da ordem da irracionalidade humana que fazem perigar os valores da eficácia e da eficiência organizacional. De resto, propósitos que a burocracia weberiana preconiza, impondo-se a si mesma uma racionalidade que compreende a 
relação entre meio e fim, com referência à relação entre causa e efeito. Baseada na lógica desta relação dirige a sua preocupação à excelência dos métodos (WEBER, 1991) e busca, incessantemente, o 'menor meio' na procura da solução ótima para se atingirem objetivos a que esta racionalidade não se dedica e não contesta, nunca pondo em causa os valores em nome dos quais se atua.

Este modo de ser racional oferece condições para que a burocracia se expresse como o modo mais capaz "de atingir o mais alto grau de eficiência" (WEBER, 1991, p. 98). A sua superioridade explica-se porque "nela se alcança tecnicamente o máximo de rendimento em virtude da precisão, continuidade, disciplina, rigor e confiabilidade" (p. 145).

Racionalidade que exclui, sem restrições, a interferência da dimensão afetiva, possibilitando erradicar qualquer resquício de erro que possa contaminar a ação organizacional, produto, como escreve Lima (1998, p. 69), "de uma determinada decisão claramente identificada, ou de uma escolha deliberada, calculada, em suma racional", o que explica a presença da impessoalidade nas relações que o trato formal concretiza por não facilitar qualquer consideração emocional. Impessoalidade que procede "em função das ordens abstractas de uma regulamentação estrita" (ARON, 1987, p. 494), fundamento da universalidade, reconhecida na tentativa que o modelo burocrático faz de singularizar o que, à partida, seria diverso.

O elemento humano transforma-se em mero acessório, retirando ao comportamento de homens e mulheres o estatuto de verdadeiro problema. Os trabalhadores são concetualizados como instrumentos "passivos capazes de executar o trabalho e receber ordens, mas sem poder de iniciativa e sem exercerem influência provida de qualquer significação" (MARCH; SIMON, 1966, p. 9). Torna-se efetiva a desvalorização a que os aspetos da organização ficam votados e tudo em prol de uma eficácia instrumental.

Nesta aceção de racionalidade, veiculada pelos modelos normativos, - comportamento dos atores organizacionais, ao ser alvo de um planeamento rígido, aspeto fundante da previsibilidade, define-se enquanto 
atividade regulada por normas e regras que coordenam, e simultaneamente, controlam e antecipam ao mesmo tempo que thes infunde constância, Ihes retira oscilações, produzindo comportamentos rotineiros, padronizados e imprime impessoalidade nas relações dos atores organizacionais. Neste quadro, há em relação ao funcionário da organização, e como consequência desta estrutura, "uma constante pressão para torná-lo 'metódico, prudente e disciplinado'" (MERTON, 1971, p. 112-113). Facto que também impõe constrangimentos comportamentais, por obrigar a uma rígida disciplina normativa e formal, tornando o trabalhador substituível por qualquer outro.

Estes pressupostos fazem assentar a organização escolar no princípio de custo-benefício, no apelo a uma educação mais eficaz e simultaneamente mais barata, numa aproximação à concetualização de escola como burocrática e empresa educativa, sendo que o uso de técnicas rigorosas ajudará na concretização de objetivos pré definidos. Com efeito, tudo fica sujeito a grande planificação e controlo. Só uma administração de ensino, que se traduz numa administração centralizada, poderá servir os intentos de coordenar a ação dos atores educativos no sentido da uniformização, que excluí, à partida, qualquer possibilidade de contestação.

Neste âmbito, o conceito de querer em nada é estranho à vontade de dominar, ou seja, é como se o processo decisório estivesse sujeito a leis que regulam a sua ordem e que, consequentemente, estabelecem o seu determinismo, sendo-lhe estranho qualquer vestígio de imprevisibilidade, ou conexões inesperadas porque tudo é previsível. Dentro desta lógica diríamos que todo o sistema de ensino que se encontra subjugado a esta relação de poder, numa nítida separação entre governantes e governados, consolida um processo marcado por opressões e dita valores em forma de receituário numa identificação cega com o coletivo. Diríamos que a componente do desempenho sobre a componente da compreensão reitera a instrumentalização da educação num claro condicionamento do 
comportamento dos atores educativos que se encontram cercados pela lógica da preservação do poder, mais do que com a sua justificação.

\section{A QUEM SERVEM AS PLATAFORMAS INFORMÁTICAS NA ESCOLA?}

Esta racionalidade instrumental, que se expressa numa experiência permeada pela uniformização, presente na escola burocrática, e que é a concretização da hegemonia da cultura dominante, é igualmente veiculada pelas plataformas informáticas que têm granjeado uma inquestionável importância pela centralidade das funções, marcando o compasso da dinâmica organizacional, extrapolando para fora do contexto de sala de aula, ao mesmo tempo que intensifica o controlo sobre o trabalho do professor através da utilização das técnicas de gestão. Deste quadro assomam, por isso, novas formas de relacionamento e comunicação entre Ministério da Educação/escola; diretor/professores; professores/professores; professores/pais, professores/alunos e vice-versa, fazendo-nos, também, questionar a 'nova interpessoalidade' que daqui resulta.

Este relevo não acontece à margem do estatuto de omnipresente que as tecnologias de informação e comunicação foram adquirindo, fruto de um crescente desenvolvimento que se estendeu por todas as áreas da sociedade, não deixando a educação incólume a esta penetração. Circunstância preconizada e promovida por uma agenda política assente nos princípios de modernização, racionalização e otimização que terá tido no "Plano Tecnológico", prioridade do XVII Governo Constitucional, a sua expressão. Apresentado como um instrumento ao serviço dos desafios que Portugal enfrentava, as estratégias de crescimento e competitividade apresentadas apostavam num reforço da importância da qualificação dos cidadãos para a sociedade do conhecimento, na necessidade de ultrapassar o atraso científico e tecnológico e no renovado fôlego imprimido à inovação.

A organização escolar vê-se, neste quadro, invadida pelas tecnologias quer ao nível do planeamento, organização, coordenação e demais 
funções administrativas. Tarefas que são realizadas à custa de software e aplicações informáticas disponibilizadas por empresas certificadas pelo Ministério da Educação e pelo próprio através do Gabinete Coordenador do Sistema de Informação, vulgarmente conhecido por MISI. Em paralelo, e expressando a mesma exaltação pelas tecnologias, as próprias escolas desmaterializam e, simultaneamente, automatizam outras tarefas e procedimento dos quais destacamos o registo de sumários, de atas, as entradas e saídas de alunos, as matrículas, etc., que instalam a ideia de padronização e consequente uniformização.

As designações das plataformas por área de incidência nas escolas, nomeadamente do âmbito da "Gestão de Alunos", da "Gestão de Pessoal, da "Gestão Administrativa", da "Gestão de Oferta Formativa" e da "Gestão Financeira", permitem dar conta da redundância informativa inserida, com consequências para o tempo gasto para preenchimento, validação e outras tarefas, por parte dos recursos humanos das escolas.

Mas se o conhecimento das dinâmicas organizacionais, promovidas pelas plataformas informáticas permite dar conta da interação estabelecida entre Ministério da Educação e escolas, que se carateriza por ser hierarquizada, no caso de cima para baixo, os manuais do utilizador, disponibilizados pelo governo central, também evidenciam o seu desígnio de centralização decisória, de controlo, de uniformização e de otimização. Conceitos caros ao propósito de modernização. Objetivos que denunciam as diversas influências ideológicas e políticas de que a escola pública tem sido alvo. 
FIGURA 1 - Objetivos do poder central com as Plataformas Informáticas para

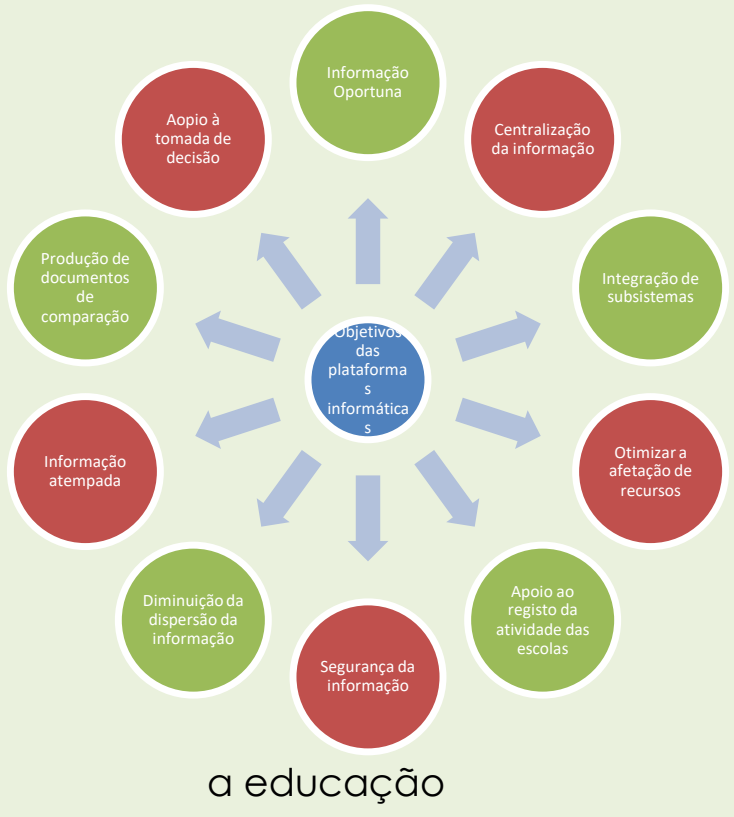

Fonte: Catalão; Pires, 2020.

As plataformas informáticas instituem-se enquanto "the one best way" na resolução de problemas, ao mesmo tempo que configuram o "menor custo" da ação organizacional, promovendo a despolitização da decisão política, mas mantendo-se a centralidade do Estado, apesar de reconfigurado.

Na verdade, este fenómeno traduz-se

numa burocracia escolar radicalizada, ampliada, ou, [...], numa hiperburocracia, aliás induzida e reforçada pelas novas tecnologias da informação e comunicação, que emergem como uma espécie de nova fonte de controlo centralizado, eletrónico e aparentemente difuso, mas contudo poderoso, sempre presente em cada momento e em todos os lugares, isto é, de natureza totalizante e, por vezes, quase totalitária (LIMA, 2012, p.11).

Realidade que também promove uma nova conceção de espaço e tempo por parte de atores educativos, mesmo os não especializados, na sua manipulação (PASCUAL, 2003), tornando efetiva a ausência de limites, pois a sua transgressão é o meio que rompe com as fronteiras espácias e que altera as relações de poder (BAUMAN, 2004). 
A este propósito escreve Virilio (2000, p. 18) que

O próprio poder da velocidade absoluta é de ser também o poder absoluto, o controlo absoluto, instantâneo, isto é, um poder quase divino. Hoje, empregamos os três atributos do divino: a ubiquidade, a instantaneidade, a imediatidade; a omnividência e a omnipotência.

Reconhecida a amplificação do controlo do centro sobre as práticas dos professores, sejam de natureza administrativa ou pedagógica, como se de um "big brother" se tratasse, em virtude da sua constante "vigilância", ficamos próximos do entendimento de Friedberg (1993) quando entendia que esta circunstância postula decisores omniscientes e um mundo transparente.

Neste enquadramento, a autonomia dos professores é um conceito vazio de sentido pelo facto de este não exercer qualquer tipo de influência neste processo. O que se pretende é mesmo eliminar qualquer espaço de decisão autónoma e transformar os professores em executantes passivos, engrenagens de uma máquina, convertendo os órgãos internos da escola a meras extensões da administração central, a quem cumpre acatar as diretrizes superiores, e uma escola obcecada pela ordem, pois por ela são julgados.

Na verdade, algumas investigações realizadas (PEREIRA, 2009; MEIRA, 2017; CATALÃO, 2019; GODINHO, 2020) dão conta, genericamente, de que não existe uma relação de causa e efeito entre informatização e desburocratização e autonomia.

Mas as plataformas informáticas, como a informática em sentido lato, facilitam, na opinião de Lima (201 1, p. 145), a

[...] invasão da esfera pessoal e doméstica [...] no que se refere à intervenção crescente na vida privada dos trabalhadores levada a cabo pelo fordismo; tudo, agora é local de trabalho, e em qualquer circunstância temporal, dada a permanente disponibilidade e acessibilidade, ou estado de prontidão dos trabalhadores [...] possibilitada pela internet. 


\section{DESENHO DE INVESTIGAÇÃO}

Neste estudo foi nossa pretensão conhecer o impacto das plataformas informáticas nas dinâmicas da organização escolar, traduzido no seu desempenho, em termos de eficiência e eficácia, à custa das representações dos atores educativos. Neste âmbito, foi elaborada a seguinte pergunta de partida:

As plataformas informáticas concorrem para reforçar ou superar a burocracia na organização escolar?

Compreendeu uma opção metodológica de natureza qualitativa visando uma compreensão global de um particular fenómeno sem dispensar uma abordagem interpretativa da ação humana, pois todo o significado só tem existência na relação dependente que estabelece com o sujeito. Os factos são determinados pelos contextos, pelo que a realidade estudada só aí faz sentido.

Para o efeito usamos o estudo de caso, um Agrupamento de Escolas situado no Norte de Portugal, situado num concelho cuja evolução demográfica tem apresentado um declínio que tem vindo a ser muito notório desde o ano de 1980. É o resultado do somatório de agregações que foram ocorrendo de forma paulatina desde o início da década de oitenta, em virtude das imposições legais que foram surgindo.

É responsável pelas respostas educativas de todos os alunos residentes na parte Este do Concelho, o que favorece a presença, para além dos oriundos das zonas urbanas, de um elevado número de alunos oriundos das zonas rurais.

De acordo com dados inclusos no Projeto Educativo, o número total de alunos ronda os dois mil para um total de mais de duzentos docentes, dos quais duzentos e trinta e três pertencem ao quadro de escola; vinte e oito ao quadro de zona pedagógica e quinze são contratados. Daqui se conclui tratar-se de um quadro docente estável cuja faixa etária está maioritariamente situada acima dos quarenta e cinco anos, com uma experiência profissional de mais de vinte e cinco e trinta anos. O número de pessoal não docente situa-se nos 74 . 
A recolha de dados realizou-se entre o período que mediou entre 2018-2019, tendo-se feito uso da entrevista semiestruturada realizada a alguns interlocutores considerados por nós como privilegiados, com cargos e sem cargos, nos quais se incluí a diretora (E1), subdiretor (E2), dois adjuntos (E3 e E4), um coordenador do Centro Escolare (E5) e dois professores sem cargos (E6 e E7).

A entrevista tem a vantagem de adaptabilidade e de proporcionar a exploração de algumas ideias, percepções, interpretações ou experiências que o entrevistado cede na sua própria linguagem (QUIVY; CAMPENHOUDT, 1998). É o que se afigura como importante e significativo, o modo como eles classificam e experimentam o mundo que se constitui como foco de interesse para o entrevistador.

Para a análise e interpretação de dados, a nossa opção recaiu sobre a análise de conteúdo, por ser "ser uma técnica que aposta claramente na possibilidade de fazer inferências interpretativas a partir dos conteúdos expressos, uma vez desmembrados em 'categorias', tendo em conta as 'condições de produção' desses mesmos conteúdos, com vista à explicação e compreensão dos mesmos" (AMADO; FERREIRA, 2017, p. 300).

QUADRO 1 - Dimensões, categorias e subcategorias para a de análise de conteúdo das entrevistas

\begin{tabular}{|l|l|l|}
\hline Dimensões & \multicolumn{1}{|c|}{ Categorias } & \multicolumn{1}{c|}{ Subcategorias } \\
\hline \multirow{4}{*}{$\begin{array}{l}\text { Controlo/ } \\
\text { autonomia }\end{array}$} & Mais controlo/mais autonomia \\
\cline { 3 - 3 } & \multirow{3}{*}{ Burocracia } & Menor Controlo/menor autonomia \\
\cline { 3 - 3 } & Agiliza procedimentos \\
\cline { 3 - 3 } & Facilita a ação posterior \\
\cline { 3 - 3 } & Torna a organização mais eficiente e ficaz \\
\cline { 3 - 3 } & Não tem implicações \\
\hline \multirow{2}{*}{ Comunicação } & Melhor Comunicação \\
\cline { 3 - 4 } & & Pior Comunicação \\
\hline
\end{tabular}




\section{ANÁLISE DE DADOS}

A utilização das plataformas informáticas por parte dos atores educativos é uma realidade que se torna indispensável pela imediata constatação da sua imposição por parte do Ministério da Educação. Com efeito, os entrevistados são todos peremptórios quando questionados sobre a sua utilização e importância para o quotidiano da escola, o que encontra corroboração nas palavras de El quando diz "que o seu dia começa com a abertura de uma qualquer plataforma, porque todos os dias há sempre o que preencher, em relação a alunos, a professores, a questões financeiras, etc...". De resto parece haver unanimidade por parte dos entrevistados relativamente à sua proliferação, pois "há sempre mais uma plataforma nova" (E3). Plataformas que nem sempre parecem ser de fácil utilização, sendo que os próprios manuais de utilização carecem de alguma simplificação. Alguns interlocutores são de opinião de que seria necessária uma formação ministrada pela tutela que pudesse minorar as dificuldades na sua utilização, pois o que se verifica é que quando "elas existem, são muito incipientes" (E1). A experiência no seu uso vai facilitando a relação entre plataforma e utilizador, mas "quando temos algum colega de novo na equipa há sempre queixas e frustrações que levam os colegas, enquanto não entram naquela dinâmica, a recorrerem constantemente a quem já cá estava" (E2). Pois "elas nem sempre são assim tão intuitivas, apesar de podermos dizer que há algumas melhorias nos últimos anos" (E1). Talvez aqui resida o motivo pelo qual a diretora sinta como necessário ter alguém na sua equipa que tenha uma formação especializada em informática, pois reconhece que "quem entende de informática tem outra disponibilidade mental para descobrir como fazer, muitas vezes também eles lá cheguem por tentativa e erro" (E1). A generalidade dos interlocutores considera que o trabalho a que as plataformas obrigam é muito extenuante, cansativo e moroso, dando conta de que "[...] nos faz sentir a necessidade de estar sempre ligados" (E4). De resto, os nossos interlocutores não sentem que a sua vida tenha sido simplificada à custa das mesmas, na medida em que repetem 
[...] muitas vezes o trabalho feito numa plataforma em outra plataforma, porque há plataformas que pedem as mesmas informações e não permite exportar informação automaticamente. O mesmo acontece a informação que inserimos no ano anterior e que nos é novamente solicitada e não nos permitem exportar informação, pois temos que preencher tudo de novo (E1).

Esta afirmação produzida encontra um outro eco quando E3 lembra que muito é exigido à classe docente em prejuízo da sua vida e estabilidade pessoal, pois "faz-se muita coisa devido à boa vontade de cada um de nós, é o amor à camisola".

De tal modo enraizadas e impossíveis de ignorar, verifica-se que a sua utilização é distribuída pela sua equipa, como confirma E2 quando diz que "Muitas vezes entro com a minha password pessoal, mas outras vezes com a da diretora" e E4 quando refere "ainda hoje não usei a password pessoal, mas a de um colega, pois temos que terminar um preenchimento". Todavia, a utilização de plataformas também se estende ao quotidiano dos docentes sem cargos que sobre elas têm uma opinião pouco favorável ao reconhecerem mais assoberbados de burocracia. A este propósito refere E7: "[...] é sumários, é atas, é formulários para tudo e mais alguma coisa. As próprias escolas parecem não viver sem plataformas para tudo e mais alguma coisa. Já bastava o Ministério da Educação".

Consideração que permite a verificação do entusiasmo e adesão das escolas às tecnologias, que saltaram as barreiras das salas de aula e entranharam-se nas dinâmicas da organização, quase sem exceção. Também importa dar nota de que os interlocutores sem cargos não reconhecem que a burocracia na escola, em consequência da informatização, tenha diminuído, "[...] antes pelo contrário, agora são as plataformas e são os papeis" (E6), pensamento que é corroborado pelos Interlocutores com cargos, pois continuam a ser de opinião que as plataformas não tornaram a escola menos burocrática, pois os papeis continuam a ter uma existência real, e são constantemente assoberbados 
"[...] por novas diretrizes, nova legislação, novas imposições, é um sem fim de imposições" (E4).

Mas também se sentem mais controlados, situação parece encontrar justificação nos prazos que são estabelecidos e que acabam por ter um efeito controlador sobre os atores educativos, pois caso "[...] não se respeitem os prazos, acabou" (E3). Assim sendo, as plataformas informáticas apresentam-se como um mecanismo de controlo, na medida em que assumem uma orientação mecanicista de verificação dos procedimentos de ordem técnica, num sério elogio à ação burocrática da administração. Obrigam a um agir representativo da impessoalidade, uniformidade e rigidez e valorizam as soluções fragmentadas pelos procedimentos burocráticos que se apresentam como que descontextualizados porque não têm relação com o todo.

Estas plataformas passam a gozar do estatuto de big brother ao reforçarem o sentido omnipresente do poder do centro, permitindo-nos conjeturar sobre a possibilidade de ser um método controlador sobre pessoas em quem não se confia em plenitude, pois não se pode confiar em quem não se conhece e que, hipoteticamente, pode não estar empenhado nos objetivos da organização escolar. As plataformas vão-se instituindo como práticas controladoras que favorecem a padronização e, consequentemente, a quantificação dos resultados. Esta padronização que adquire contornos de uniformização não deixa lugar à individualização, tornando-as iguais mesmo quando as diferenças começam longo pela diferente grandeza dos agrupamentos de escola. E se vistos como iguais não se tem em conta que a informação a inserir relativa a duzentos professores tenha um gasto de tempo superior a um agrupamento de escolas com cem professores, o que vale para os alunos e pessoal não docente, pois os prazos a que se "[...] tem que obedecer são os mesmos e por vezes prazos demasiado apertados" (E2).

Deste quadro não podemos deixar de aludir a um controlo que em muito se aproxima da falta de autonomia, que parece ter invadido a esfera da gestão quotidiana em assuntos aparentemente pouco valorizados, mas 
altamente indispensáveis ao bom funcionamento da organização escolar, como a simples compra de material escolar. Para este efeito "há uma plataforma para compra de material, e não há como fugir, estamos obrigados a comprar aquele e não outro qualquer, porque aquele que estamos obrigados a comprar é sempre o mais barato, mesmo que isso signifique que a relação qualidade preço não exista, é sempre de qualidade duvidosa, fraca. E isso torna mais caro o material, pois como nada funciona temos que voltar a comprar outras, nem essa autonomia nós temos" (E5). Parece generalizar-se a ideia, em torno das representações dos interlocutores, de que não são as plataformas informáticas que torna as escolas mais eficientes e mais eficazes pois, como expressa E7, "não vejo que a escola tenha passado a funcionar melhor porque agora há plataformas, até porque as utilizadas pela diretora não as conheço, nem quero conhecer!".

Esta desconfiança na autonomia dos professores reflete bem os limites que se impõem à capacidade de autogoverno, mesmo no que respeita à realização do trabalho pedagógico e, neste caso, faz-nos cair na conta que para aumentar a autonomia das escolas é impreterivel aumentar, a diferentes níveis, os poderes de decisão da escola.

A este controlo que as plataformas favorecem não podemos deixar de associar a dimensão de impessoalidade que a comunicação inclui. Impessoalidade que procede, como refere Aron (1987, p. 494), "em função de ordens abstractas de uma regulamentação estrita", fundamento da universalidade, reconhecida na tentativa que a burocracia faz de singularizar o que, à partida, seria diverso. Uma impessoalidade reforçada pelo distanciamento do Ministério da Educação o que, por si só, dificulta a comunicação. De resto, uma comunicação desprovida de qualquer consideração de natureza afetiva, o que impede a fricção entre as partes. É o tempo da "frieza da tecnologia" associado à "soberania da tecnocracia". Acresce a esta situação o facto de nem sempre esta comunicação ocorrer, pois os 
[...] canais do Ministério estão sempre ocupados, se eu tenho alguma dúvida eu uso o mesmo meio que uma outra qualquer pessoa para obter esclarecimentos, e por isso sei que vou ter que esperar imenso tempo para que do outro lado alguém, diga laguma coisa, e isto é desesperante (E1).

As práticas parecem contrariar a inexistência de autonomia efetiva ou politicamente consagrada. Sabemos que a autonomia de que os atores educativos dispõem depende, em grande parte, da percepção que têm dessa autonomia, mais do que da sua efetiva existência. Se perpassa a ideia de que não existe autonomia, ninguém anda à procura de explorar margens de autonomia, pois ninguém procura o que acredita não existir.

Este trabalho levado a cabo potenciado pelo uso das plataformas informáticas pode justificar a ideia de que o diretor se aproxima da figura de um gestor, dada a importância que é atribuída ao funcionamento da organização escolar no sentido mais técnico, assumindo-se a importância do conhecimento especializado, dando-se relevância a um governo da organização que incide sobre o tecnicismo a que a mesma obriga, mesmo que se considere relevante associar o conhecimento da realidade educacional. Porém, a ideia de que é mais um gestor do que um professor encontra fundamento no trabalho administrativo/burocrático que tem em mãos. A este propósito refere E6:

[...] quase nos esquecemos que a diretora é uma colega. Deixou de dar aulas, vive no gabinete à volta de burocracia, faz-me pensar que as suas preocupações estão mais próximas da preocupação de um gestor. Mas isso não significa que não esteja preocupada com a parte pedagógica da escola e com os professores.

\section{CONCLUSÃO}

Num tempo que reclama de maior eficiência e eficácia ao nível das organizações escolares foi possivel dar conta de que as escolas se encontram permeadas pelas plataformas informáticas e pela ideia de que o seu uso garante melhor e mais gestão. 
Todavia, as representações dos interlocutores puseram a descoberto o excessivo trabalho que elas vieram impor ao quotidiano escolar, em particular no que concerne ao trabalho da diretora e da sua equipa, agora com tarefas a realizar em tempos limitados e definidos pelo Ministério da Educação.

Plataformas que permitiram à tutela uma maior monitorização do trabalho realizado, numa clara preocupação com a obediência às regras e procedimentos por si impostos.

Se por um lado as plataformas informáticas, pela padronização e uniformização de procedimentos, pelos tempos limitados na inserção da informação deixam antever a presença da burocracia no agrupamento de escolas em estudo, por outro lado a eficiência e a eficácia não se têm sentido enquanto seu impacto, em virtude do reconhecimento da sobrecarga de trabalho, da inserção da mesma informação em plataformas diferenciadas, sendo que o papel continua a ter um lugar cativo, sem que fosse perceptível a clareza e simplificação de processos, considerações que não abonam em favor da modernização da organização escolar.

\section{REFERÊNCIAS}

AMADO, J.; FERREIRA, S. A entrevista na investigação em educação. In: AMADO, J. (Org.). Manual de investigação qualitativa em educação. Coimbra: Imprensa da Universidade de Coimbra, 2017. p. 207-232.

ARON, R. As etapas do pensamento sociológico. Brasília: Livraria Martins Fontes Editora, 1987.

BAUMAN, Z. Liquid modernity. Cambridge: Polity Press, 2004.

BURREL, G., MORGAN, G. Sociological Paradigms and Organizational Analysis: Elements of the Sociology of Corporate Life. Brookfield: Ashgate, 1992.

CATALÃO, A. O papel das plataformas informáticas na regulação da organização e gestão da escola. 2019. Dissertação (Mestrado em Ciências da Educação - Administração Educacional) - Instituto Politécnico de Lisboa, Escola Superior de Educação, 2019. 
CATALÃO, A.; PIRES, C. As plataformas informáticas como instrumentos de regulação da organização e gestão escolar. Revista Portuguesa de Investigação Educacional, [S. I.], p. 85-110, 2020. DOI:

10.34632/investigacaoeducacional.2020.8502

FRIEDBERG, E. O poder e a regra. Dinâmica da ação organizada. Lisboa: Instituto Piaget, 1993.

GODINHO, R. As plataformas Informáticas na gestão escolar: burocracia ou autonomia. 2020. Dissertação (Mestrado em Ciências da Educação Administração Educacional) - Instituto de Educação da Universidade do Minho, Braga, 2020.

LIMA, L. A escola como organização e a participação na organização escolar. Um estudo da escola secundária em Portugal (1974-1988). Braga: Universidade do Minho, Instituto de Educação e Psicologia, 1998.

LIMA, L. Elementos de hiperburocratização da administração educacional. In: LUCENA, C.; SILVA JÚNIOR, J. R. (Orgs.). Trabalho e educação no Séc. XXI: experiências internacionais. São Paulo: Xamã, 2012.

LIMA, L. Políticas educacionais, organização escolar e trabalho dos professores. Educação: Teoria e Prática, v. 21, n. 38, p. 1-18, 2011.

MARCH, J.; SIMON, H. Teoria das organizações. Rio de Janeiro: Fundação Getúlio Vargas, 1966.

MEIRA, M. A burocracia electrónica: um estudo sobre as plataformas electrónicas na administração escolar. 2017. Dissertação (Mestrado em Ciências da Educação - Administração Educacional) - Instituto de Educação da Universidade do Minho, Braga, 2017.

MERTON, R. Estrutura burocrática e personalidade. In: CAMPOS, E. (Org.), Sociologia da burocracia. Rio de Janeiro: Zahar Editores, 1971. p. 107-124.

PASCUAL, P. J. e-Government. Manila: e-ASEAN, 2003. Disponível em: http://en.wikibooks.org/wiki/E-government. Acesso em: 29 de jun. de 2008.

PEREIRA, C. Ciberadministração educacional e identidade docente: dinâmicas de poder e lógicas de sobrevivência. 2009. Dissertação (Mestrado em Ciências da Educação - Administração Educacional) - Instituto de Educação da Universidade do Minho, Braga, 2009.

QUIVY, R.; CAMPENHOUDT, L. V. Manual de investigação em ciências sociais. Lisboa: Editora Gradiva, 1998. 
VIRILIO, P. Cibermundo: A política do pior. Lisboa: Editorial Teorema, 2000.

WEBER, M. Economia e sociedade. Fundamentos da sociologia compreensiva. Brasília: Editora Universidade de Brasília, 1991.

Recebido em: 15 de setembro de 2020.

Aprovado em: 20 de março de 2021.

Publicado em: 26 de abril de 2021.

(c) (i) 